\title{
DUP1 peptide modified micelle efficiently targeted delivery paclitaxel and enhance mitochondrial apoptosis on PSMA-negative prostate cancer cells
}

\author{
Haining Chen ${ }^{1 \dagger}$, Fengbo $\mathrm{Wu}^{1 \dagger}$, Jing $\mathrm{Li}^{1 \dagger}$, Xuehua Jiang ${ }^{3}$, Lulu Cai ${ }^{1,2^{*}}$ and Xiang $\mathrm{Li}^{\mathrm{i}^{*}}$
}

\section{${ }^{*}$ Correspondence:}

cll_sc@163.com;

xiangli.87@scu.edu.cn

${ }^{\dagger}$ Haining Chen, Fengbo

Wu and Jing Li contributed

equally to this work

${ }^{1}$ Department

of Gastrointestinal Surgery,

Department of Urology,

Department of Pharmacy

and State Key Laboratory

of Biotherapy, West China

Hospital, Sichuan University,

Chengdu 610041, China

Full list of author information

is available at the end of the article

\begin{abstract}
Prostate tumor cell targeted peptide fragment conjugated to the nano drug delivery system is a promising strategy for prostate cancer therapy. In this work, an amphiphilic copolymer Chol-PEG-DUP1 (PEG-cholesterol conjugated with DUP1 peptide) has been synthesized and characterized by proton nuclear magnetic resonance spectrum ('H NMR). The paclitaxel (PTX) was encapsulated into the Chol-PEG-DUP1 micelles to obtain aqueous formulation with small particle size (within $200 \mathrm{~nm}$ ) and high drug encapsulating efficiency. The DUP1 modified PTX micelle significantly enhanced the cytotoxicity of paclitaxel to PSMA negative prostate tumor cells (PC-3 cell) as demonstrated by MTT ( $\left(\mathrm{C}_{50}=15.8 \mu \mathrm{g} / \mathrm{mL}\right.$ compared to $68.7 \mu \mathrm{g} / \mathrm{mL}$ of free PTX). Flow cytometry analysis and fluorescence images revealed the DUP1 peptide fragments on the surface of micelles increased drug uptake (2.08-fold) by PC-3 cells. Flow cytometry and immunoblotting analysis showed the DUP1 modified PTX micelle enhanced the mitochondrial apoptosis-inducing capacity of PTX to PC-3 cells. In conclusion, Chol-PEGDUP1 modified micelle was a reasonable, facile, and economic drug delivery system to target the PSMA-negative prostate cancer.
\end{abstract}

Keywords: Drug delivery, Amphiphilic polymer, Paclitaxel, PSMA-negative, Micelle

\section{Background}

Nowadays, prostate cancer is one of the main lethal cause from cancer patients worldwide, and more than one-third of newly diagnosed male cancer in Europe and USA was prostate cancer (Crawford 2003; Parkin et al. 2001). Despite the hormone therapy was effective in early stage, many patients with metastatic potential eventually progress to an androgen-resistant state (Sandblom and Varenhorst 2001; Zitzmann et al. 2005). Although there were several treatment methods applied in the clinic, but none showed a survival benefit in hormone independent prostate cancer patients (Sternberg 2003).

Prostate-specific membrane antigen (PSMA) as a member of trans-membrane folate hydrolase family, which could enhanced the expression level in prostate cancer tissue other than benign or neoplastic epithelial prostate cells (Bostwick et al. 1998; Ross et al. 2003). A weak extra prostatic expression of PSMA has been reported in some

(C) 2016 Chen et al. This article is distributed under the terms of the Creative Commons Attribution 4.0 International License (http:// creativecommons.org/licenses/by/4.0/), which permits unrestricted use, distribution, and reproduction in any medium, provided you give appropriate credit to the original author(s) and the source, provide a link to the Creative Commons license, and indicate if changes were made. 
other tissues (Renneberg et al. 1999; Silver et al. 1997) Therefore, the Hu591 monoclonal antibody $(\mathrm{mAb})$ targeting the PSMA extracellular domain, has been applied to the prostate cancer therapy (Liu et al. 1997; Nanus et al. 2003). An ${ }^{111}$ In-labeled monoclonal antibody (Capromab pendetide, ProstaScint) could targeted to PSMA and used for imaging lymph node metastases. Recently, Zitzmann et al., have reported a novel peptide DUP1 with specificity for PSMA-negative prostate tumor cell lines, such as DU-145 and PC-3, which was identified by phage display techniques.

Peptide modified polymeric micelles have been investigated extensively, and these works are quite extraordinary, impressive, and laid a solid foundation for our study. In recent years, Torchilin et al, have reported that the monoclonal antibody (mAb)-modified PEG-PE micelles could recognize and bind to numerous tumor cells but not normal cells in vitro (Torchilin et al. 2003). Several researchers have reported that the synergetically therapeutic efficacy of chemotherapy by polymer-peptide or drug-peptide conjugates, which leads to amplifying apoptosis induction activity in the tumor or enhancing tumor targeting (Liu et al. 2008; Dharap et al. 2005). In our previously studies, we have reported the fibroblast growth factor (FGF) fragment peptide modified micelles could significantly enhanced the cytotoxicity of paclitaxel for murine lewis lung cancer (LLC) cells, which were further confirmed by some subsequent experiments in vitro (Cai et al. 2011). These antibodies or peptides conjugated micelles could enhanced the specific uptake of drugs and/or genes by targeted cells actively. To our knowledge, nanotechnology is widely applied to prepare a novel nano-formulation of hydrophobic drugs for enhancing cancer therapy efficiency (Gong et al. 2013). By encapsulating into nanoscale vectors, hydrophobic drugs could form stably disperse morphology in water (Wagner et al. 2006; Jain and Stylianopoulos 2010; Li et al. 2012). Moreover, amphiphilic polymeric micelles have widely applied in drug delivery system (DDS) for anti-tumor agents, in which the hydrophilic shell helps the escape from the clearance by RES (reticuloendothelial system) and the hydrophobic core wraps drug via hydrophobic interactions or hydrogen bonds (Gong et al. 2010, 2011; He et al. 2012; Li et al. 2012, 2013; Wu et al. 2012; Ma et al. 2013; Zhang et al. 2014; Zeng et al. 2014). Furthermore, their nano-size will improve the anti-tumor effects through the enhanced permeability and retention (EPR) effect (Iyer et al. 2006; Muggia 1999; He et al. 2013).

In this work, DUP1 peptide was obtained by solid phase peptide synthesis, and DUP1 modified polymeric micelles were prepared using a solid dispersion method (Fig. 1). Cytotoxicity, apoptosis, cellular uptake, and drug release behavior of paclitaxel (PTX) loaded Chol-PEG-DUP1 micelles (Chol-PEG-DUP1-M-PTX) were studied in detail. Hence, this novel tumor targeting DDS may have several functions for prostate tumor therapy: first of all, the Chol-PEG-DUP1 micelles could provide prolonged drug effects because of their sustained release characteristic, and protect the encapsulated agent from enzymatic degradation; secondly, the nanoscale size of the micelles would improve the targeting efficiency and therapeutic activity of small molecular antitumor drug via EPR effect; finally, the DUP1 fragment could specifically target to the PSMA-negative tumor cells, resulting in special uptake of antitumor drugs. 


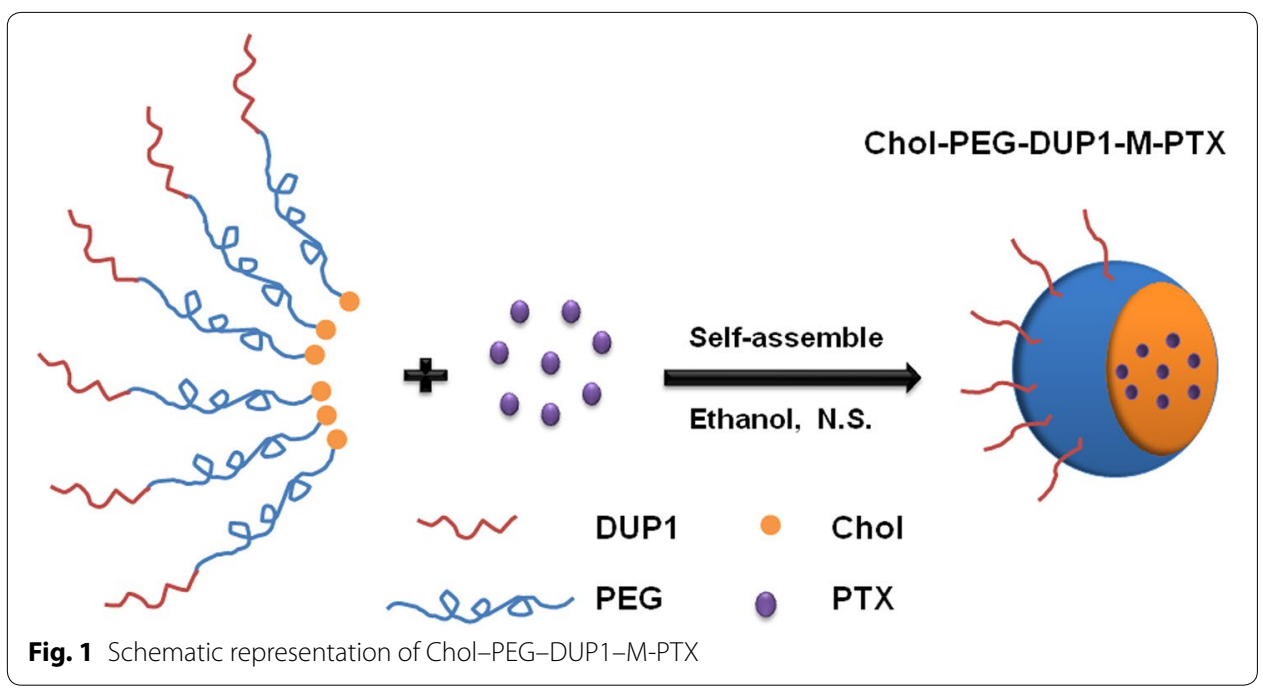

\section{Methods}

\section{Materials and cell lines}

Cholesterol (Chol) monomethoxy poly(ethylene glycol) (MW 2000, mPEG2000) and poly(ethylene glycol) (MW 2000, PEG2000), was obtained from BoAo Biological Technology (Shanghai, China). The 3-[4, 5-dimethylthiazol-2-yl]-2, 5-diphenltetrazolium bromide (MTT), 1-(3-dimethylaminopropyl)-3-ethylcarbodiimide hydrochloride (EDCI), and 4-dimethylaminopyridine (DMAP) 1, 8-Diazabicyclo(5.4.0)undec-7-ene (DBU), Coumarin-6, fmoc-L-phenylalanine (fmoc-phe), and succinic anhydride (suc) were Obtained from Sigma-Aldrich (St. Louis, MO, USA). 3-Maleimidopropionic acid $\mathrm{N}$-succinimidyl ester (BMPS) was purchased from Jiaxing Biomatix Co. Ltd. (Jiaxing, China). Soya phosphatidylcholine (SPC) was from Lucas Meyer (Hamburg, Germany). Paclitaxel (PTX) was purchased from Energy Chem. Co. Ltd. (Shanghai, China).

The DUP-1 peptide (CFRPNRAQDYNTN) was synthesised by standard solid-phase peptide synthesis method using Fmoc chemistry. The DUP1 peptide was purified by preperative high-pressure liquid chromatography on a Novasep LC50, $\mathrm{C}_{18}$-ODS- $5 \mu \mathrm{m}$, $250 \times 50 \mathrm{~mm}$ column (Novasep, Pompey, France) using water, acetonitrile and methanol as eluent solvent. All other solvents and reagents were of chemical grade and used without other purification. The ultrapure water was prepared from Milli-Q water system without specification.

PC-3 cell was purchased from the American Type Culture Collection (ATCC, Rockville, MD, USA). PC-3 cells grew in Roswell Park Memorial Institute 1640 medium (RPMI 1640, Gibco, Grand Island, NY, USA) supplemented with $10 \%$ fetal bovine serum (FBS, Gibco, USA). All cells were maintained at $37^{\circ} \mathrm{C}$ in humidified incubator containing $5 \% \mathrm{CO}_{2}$.

\section{Synthesis of cholesterol-poly(ethylene glycol)-DUP1 peptides copolymers}

The synthesis process of cholesterol-poly(ethylene glycol)-DUP1 copolymers (CholPEG-DUP1) was followed our previous report; the synthetic route was showed in Scheme 1. 


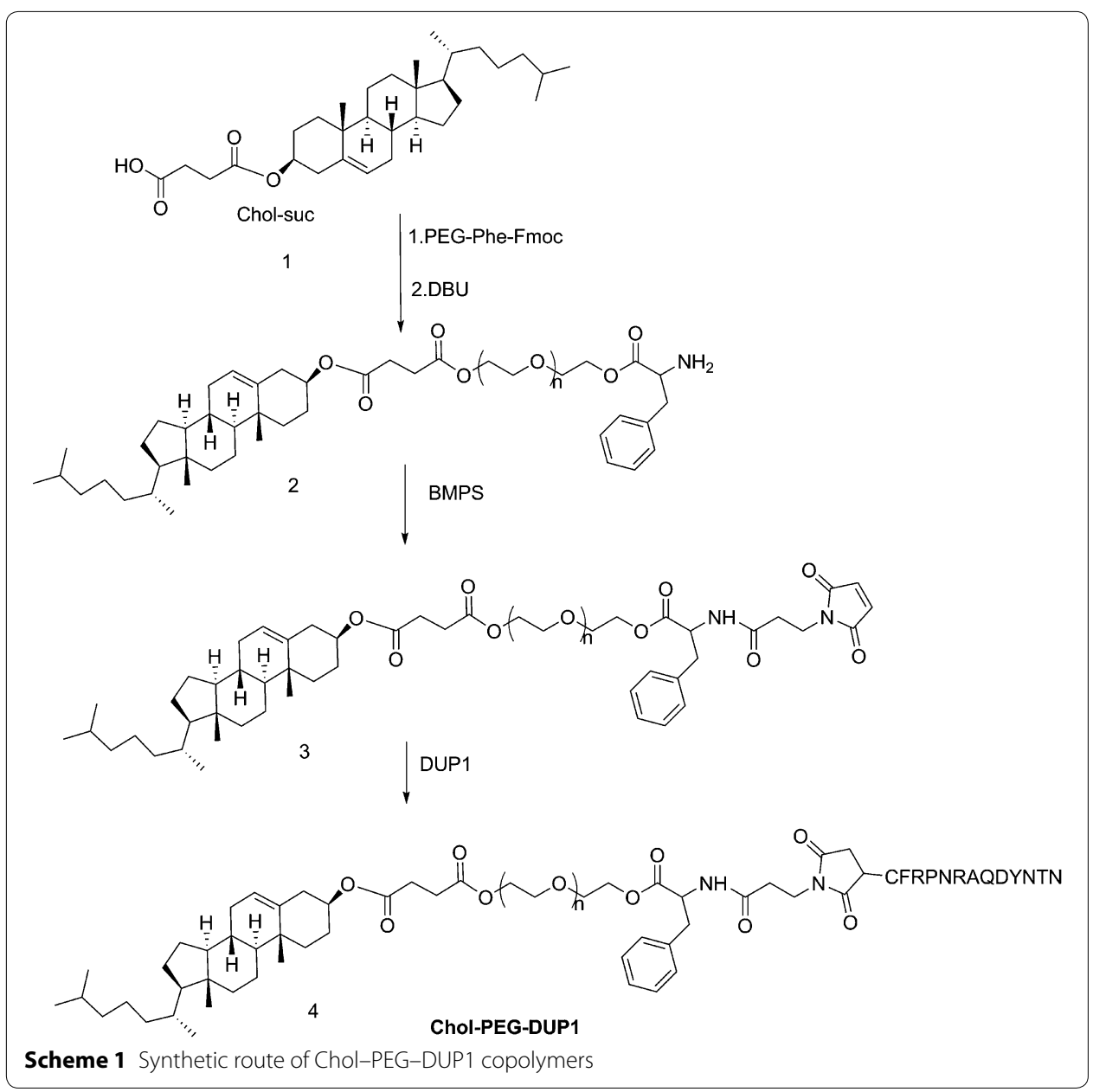

In general, the DMSO solution of Chol-PEG-Phe- $\mathrm{NH}_{2}(2.0 \mathrm{~g}, 0.76 \mathrm{mmol})$, and BMPS $(0.24 \mathrm{~g}, 0.92 \mathrm{mmol})$ was stirred $24 \mathrm{~h}$ at room temperature to give a 3-maleimidopropionic acid modification on the PEG chain. Then the DUP-1 peptide (CFRPNRAQDYNTN, $1.51 \mathrm{~g}, 0.92 \mathrm{mmol}$ ) was added and continuous stirred $12-24 \mathrm{~h}$. After the reaction was completed, the solution was dialyzed to remove un-reacted peptides (membrane tubing, molecular weight cut off $=1.0 \mathrm{KD}$ ). The dialyzed product was lyophilized and the final products Chol-PEG-DUP1 (1.42 g, $47.1 \%$ ) was obtained.

\section{Preparation and characterization of Chol-PEG-DUP1-M-PTX}

The paclitaxel loaded Chol-PEG-DUP1 micelles (M-PTX) were prepared as following: PTX and copolymer $(1: 19, \mathrm{w} / \mathrm{w})$ were dissolved in ethanol, and the solution was evaporated in rotary evaporator for $20 \mathrm{~min}$ to obtain the co-evaporation. Then, normal saline (NS) was added, and co-evaporation was dissolved to self-assemble into CholPEG-DUP1-M-PTX. The obtained Chol-PEG-DUP1-M-PTX was first filtered using a $0.22 \mu \mathrm{m}$ Millex-LG filter (Millipore Co., Waltham, MA, USA), and then lyophilized into powder form before use.

The Malvern Nano-ZS 90 laser particle size analyzer (Malvern, Worcestershire, UK.) was utilized to the determination of particle size distribution and zeta potential of 
Chol-PEG-DUP1-M-PTX. All the results were tested in three different samples, and data were expressed as the mean \pm standard deviation (SD). The morphological characteristic of Chol-PEG-DUP1-M-PTX was further detected by transmission electron microscope (TEM, H-6009IV, Hitachi, Tokyo, Japan). The Chol-PEG-DUP1-M-PTX sample was negatively staining by phosphotungstic acid before TEM test.

The high performance liquid chromatography (HPLC, Waters Alliance 2695, Milford, MA, USA) instrument was used to determine the drug loading (DL) and encapsulation efficiency (EE) of Chol-PEG-DUP1-M-PTX with a ultra-violet (UV) detector, and chromatographic separations were performed on a reversed phase $\mathrm{C}_{18}$ column (4.6 $\times 150 \mathrm{~mm}, 5 \mu \mathrm{m}$, Inertsil/WondaSil, Japan). The DL and EE of Chol-PEG-DUP1M-PTX were calculated according to the following equations:

$$
\begin{aligned}
& \mathrm{DL}=\mathrm{Drug} /(\text { Drug }+ \text { Polymer }) \times 100 \% \\
& \mathrm{EE}=\text { Drug in micelles } / \text { drug in feed } \times 100 \%
\end{aligned}
$$

\section{In vitro cytotoxicity}

To investigate cytotoxicity of Chol-PEG-DUP1-M-PTX and free PTX, MTT assays were preformed on PC-3 cells. PC-3 cells cultured in 96-well plates were treated with a series of Chol-PEG-DUP1-M-PTX or free PTX for $48 \mathrm{~h}$, respectively. The mean percentage of cell survival relative to that of control cells was determined from data of three individual experiments, and all the data were expressed as mean $\pm \mathrm{SD}$.

\section{Apoptosis assay}

Apoptosis induction assay of Chol-PEG-DUP1-M-PTX and free PTX were studied on PC-3 cells. PC-3 cells were plated in 6-well plates and grown for $24 \mathrm{~h}$. The cells were exposed to media containing $20 \mathrm{ng} / \mathrm{mL}$ of Chol-PEG-DUP1-M-PTX and free PTX for $48 \mathrm{~h}$, respectively. Then, the cells were fixed with pre-chilled $70 \%$ ethanol for $30 \mathrm{~min}$ and stained with $0.5 \mathrm{~mL}$ of PI ( $5 \mu \mathrm{g} / \mathrm{mL}$ in PBS) for $10 \mathrm{~min}$. Apoptotic cells were observed under fluorescence microscopy (TE2000-U, Nikon, Tokyo, Japan), which demonstrated cytoplasmic and nuclear shrinkage and chromatin condensation.

Furthermore, flow cytometric (FCM) assay was used to confirm the apoptotic induction effect of Chol-PEG-DUP1-M-PTX. Apoptosis of PC-3 cells treated with PTX -M, free PTX, or blank micelles was determined using FITC-conjugated AnnexinV/PI (BD PharMingen, San Diego, CA, USA) staining by FCM (BD FACS Calibur, BD, San Jose, $\mathrm{CA}, \mathrm{USA}$ ). Both early apoptotic (Annexin $\mathrm{V}^{+} / \mathrm{PI}^{-}$) and late apoptotic (Annexin $\mathrm{V}^{+} / \mathrm{PI}^{+}$) cells were included in cell apoptosis determinations.

\section{In vitro drug release}

The release profiles of PTX from DUP1-modified micelles or free PTX were investigated by the dialysis method. Briefly, $1 \mathrm{~mL}$ of free PTX solution or drug loaded micelles were placed into dialysis bags (molecular weight cut off $=3500$ ), then incubated at $37^{\circ} \mathrm{C}$ with gentle shaking $(100 \mathrm{rpm})$ in $50 \mathrm{~mL}$ of phosphate buffered solution (PBS) (PH 7.4 or PH 5.5, $0.01 \mathrm{M})$ containing Tween80 (0.5 wt\%). After given time intervals, dialysis medium was withdrawn and replaced with the same volume of fresh buffer. The cumulative 
amount of released PTX were analyzed and quantified by HPLC. All the results were the mean value of three test runs and all data were shown as the mean \pm SD.

\section{Cellular uptake of micelles by flow cytometry analysis}

In general, the PC-3 cells suspension $\left(6 \times 10^{4}\right.$ cells/well in $\left.1.5 \mathrm{~mL}\right)$ were incubated at $37{ }^{\circ} \mathrm{C}$ for $24 \mathrm{~h}$ in six-well plates (Corning, NY, USA). Then conventional micelles or DUP1-modified micelles loading the same amount of coumarine- 6 (the final concentrations were about $40 \mathrm{ng} / \mathrm{mL}$ ) were added into each well, respectively. Then the six-well plates were further incubated at $37^{\circ} \mathrm{C}$ for $1 \mathrm{~h}$, the culture medium was discarded, the plates were digested with trypsin and the re-suspended cells were washed with cold PBS twice. Finally, each sample was examined by a flow cytometer (EPICS Elite ESP, Beckman Coulter, Brea, CA, USA). The fluoresces of intracellular coumarin- 6 was excited at $488 \mathrm{~nm}$ with an argon laser, and the emission fluorescence was detected at $525 \mathrm{~nm}$. Files were collected of 10,000 gated events.

\section{Immuno-blotting analysis}

The cellular total proteins were extracted using RIPA buffer (SolarBio, Beijing, China) containing $1 \%(v / v)$ PMSF (SolarBio), $0.3 \%(v / v)$ protease inhibitor (Sigma, St. Louis, MO, USA) and $0.1 \%(v / v)$ phosphorylated proteinase inhibitor (Sigma). Celluar lysates were centrifuged at $13,000 \mathrm{rpm}$ at $4{ }^{\circ} \mathrm{C}$ for $10 \mathrm{~min}$, the supernatant was collected. The protein concentration was determined using BCA protein assay kit (Pierce, Waltham, MA, USA). The total protein was separated on SDS-PAGE gel and transferred onto a PVDF membrane. Non-specific interactions were blocked using skimmed milk for $2 \mathrm{~h}$ at room temperature. The PVDF membranes were incubated with the primary antibodies overnight at $4{ }^{\circ} \mathrm{C}$. After washed several times, the PVDF membranes were incubated in HRP-conjugated goat anti-rabbit and anti-mouse IgG or HRP-conjugated mouse antigoat IgG (Abmart, Shanghai, China, all at a 1:5000 dilution) for 4-8 $\mathrm{h}$ at room temperature. The target proteins were visualized using enhanced chemiluminescence (Millipore, Billerica, MA, USA) according to the manufacturer's recommendations.

\section{Results and discussion}

\section{Synthesis and characterization of paclitaxel loaded micelles with or without DUP1} modification

The synthesis of Chol-PEG-DUP1 was according to our previous reports with some modifications (He et al. 2012; Zeng et al. 2014). Figure 2 represents the ${ }^{1} \mathrm{H}$ NMR spectrum of Chol-PEG-BMPS (PEG-cholesterol conjugate of ( $\mathrm{N}$-[ $\beta$-maleimidopropyloxy] succinate) and Chol-PEG-DUP1, demonstrated the successful synthesis of Chol-PEGDUP1. As shown in Fig. 2, the multiplet peaks at $\delta 3.47-3.76$ were attributed to the methylene group of repeating ethylene glycol units in PEG, and the six- and three position protons in cholesterol were found as single peak at 5.36 and $4.59 \mathrm{ppm}$, respectively. The multiplet peaks around $4.24 \mathrm{ppm}$ were assigned to the PEG methylene protons near the succinyl group, and the multiplet peaks at 2.70 were attributed to the methylene proton of succinyl group. All of the other multiple signals at $0.68-2.05$ were the signals the protons in cholesterol. These results further showed that the conjugate had been successfully prepared. 


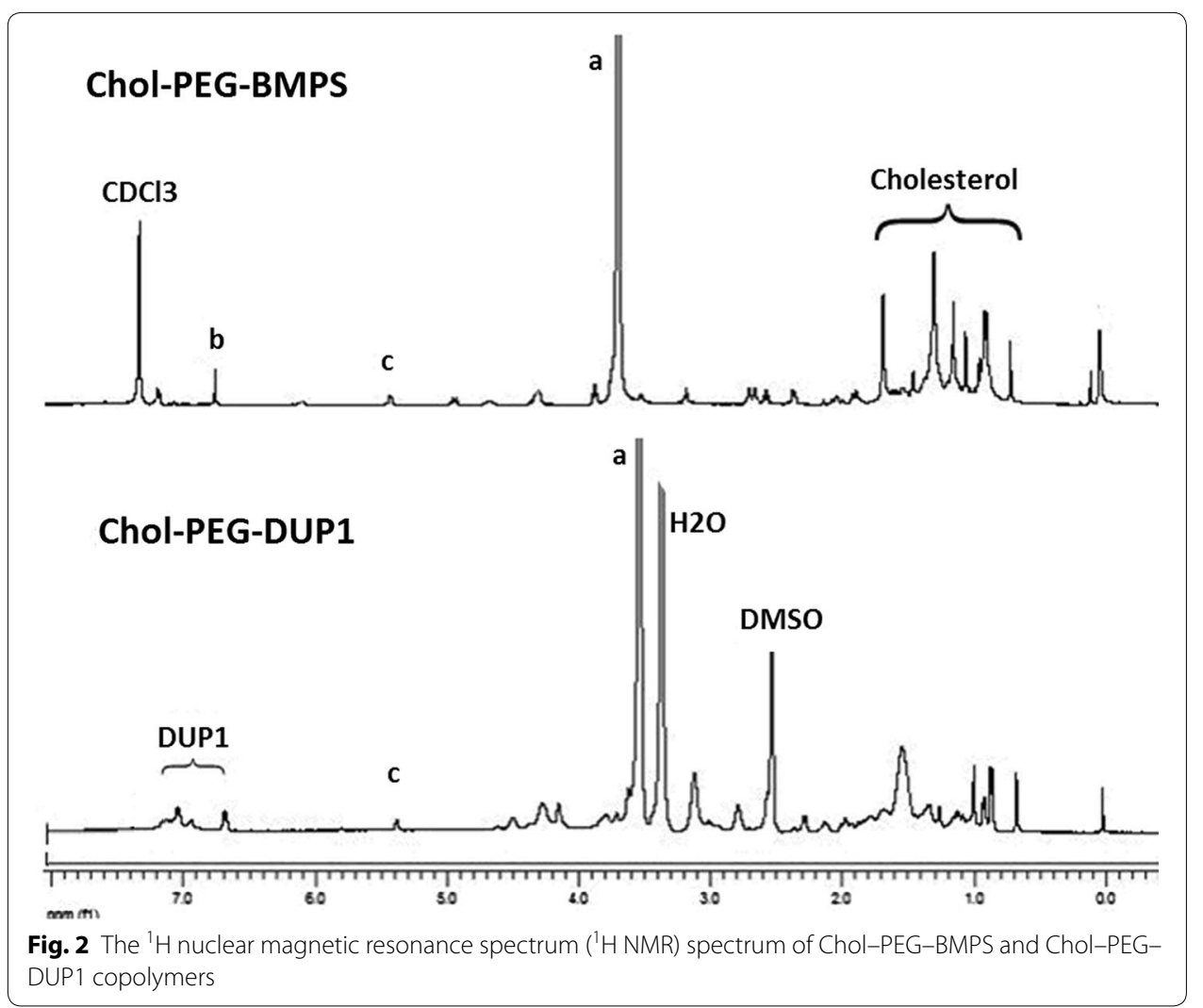

In our study, Chol-PEG-DUP1-M-PTX was prepared by a one-step solid dispersion method, the mean size of paclitaxel loaded micelles were fluctuated from 202 to $230 \mathrm{~nm}$, with the different drug/polymer $(w / w)$ ratio. The optimized polymer/drug ratio was 10:3, the optimized DL and EE were $24.9 \pm 0.6 \%$ and $96.40 \pm 1.8 \%$, respectively. Furthermore, particle size, polydisperse index (PDI), and zeta potential of obtained PTX loaded Chol-PEG-DUP1 micelles were $202.5 \pm 1.0 \mathrm{~nm}, 0.218 \pm 0.032$, and $12.6 \pm 3.4 \mathrm{mV}$, respectively (Fig. 3a, b). Transmission electron microscopy (TEM) image of Chol-PEGDUP1-M-PTX was exhibited in Fig. 3c, and it indicated that the Chol-PEG-DUP1-MPTX was spherical in shape with a diameter of about $200 \mathrm{~nm}$. The results of particle size analysis and microstructure of PTX observed by TEM suggested that a homogenous and stable solution of Chol-PEG-DUP1-M-PTX could be achieved by encapsulating PTX into polymeric micelles.

\section{In vitro drug release profile}

The in vitro release profile of paclitaxel from DUP1 peptide modified micelles (CholPEG-DUP1-M-PTX) was studied at $37{ }^{\circ} \mathrm{C}$ and $\mathrm{pH}$ 7.4. Data suggest that paclitaxel can be well encapsulated in Chol-PEG-DUP1 micelles, and released in an extended period. As shown in Fig. 4, approximately $54 \%$ of total drugs released after $24 \mathrm{~h}$, followed by release of $78 \%$ in $120 \mathrm{~h}$. This cumulative drug release suggests potential applicability of these micelles as promising DDS that could result in a content pharmacokinetic profile in vivo and reduced exposure of healthy tissues. 

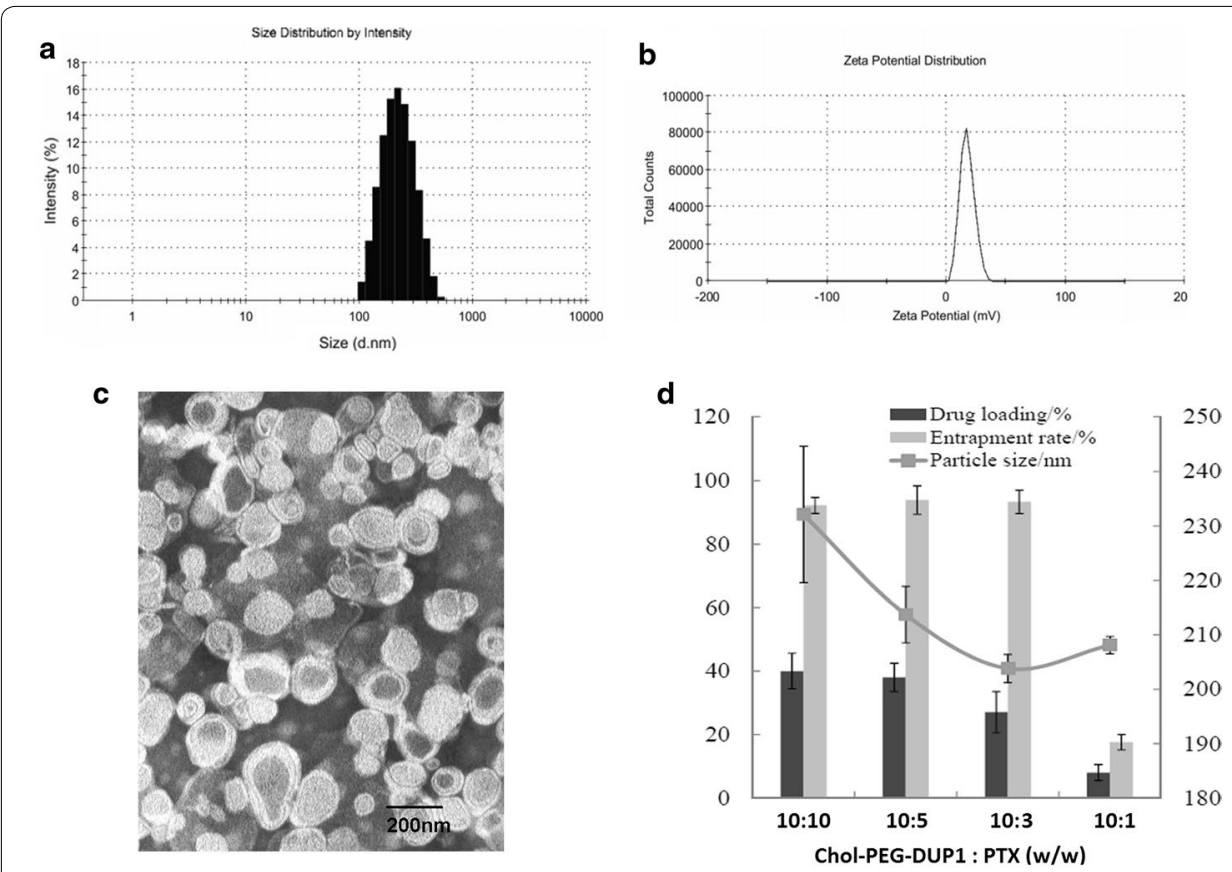

Fig. 3 Characterization of Chol-PEG-DUP1-M-PTX. a Particle size of Chol-PEG-DUP1-M-PTX; $\mathbf{b}$ zeta potential of Chol-PEG-DUP1-M-PTX; c TEM image of Chol-PEG-DUP1-M-PTX; $\mathbf{d}$ the effect of polymer/drug ratio on the encapsulation efficiency (EE), drug loading (DL) and size of Chol-PEG-DUP1-M-PTX [mean \pm SD (standard derivations), $n=3]$

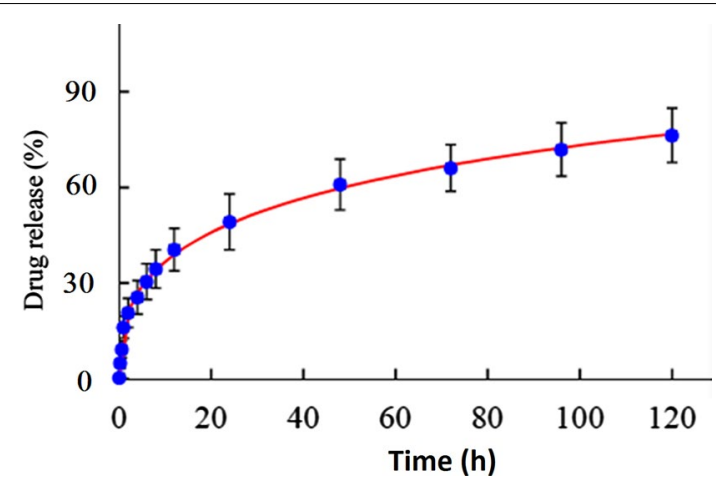

Fig. 4 Time course of paclitaxel releasing from Chol-PEG-DUP1 micelle at $37^{\circ} \mathrm{C}$ and $\mathrm{pH}$ 7.4. Released paclitaxel was separated by dialysis and quantified using high performance liquid chromatography (HPLC, error bars correspond to $95 \%$ confidence intervals)

\section{Cell uptake and binding study}

To evaluate whether DUP1 peptide fragments could increase drug uptake by PSMA negative prostate tumor cells, PC-3 cells were treated with micelles encapsulated with coumarine-6. After incubation for a specific time, the cells were washed, then identified using fluorescence microscopy and collected for analysis of coumarine-derived fluorescence by flow cytometry. The flow cytometry data (Fig. 5a) shows the distribution of intensity in PC-3 cells treated with Chol-PEG-DUP1-M-Cou, Chol-mPEG-M-Cou, or empty CholPEG2000-DUP1 micelles (Control). Mean fluorescence intensity of coumarine-6 uptake 

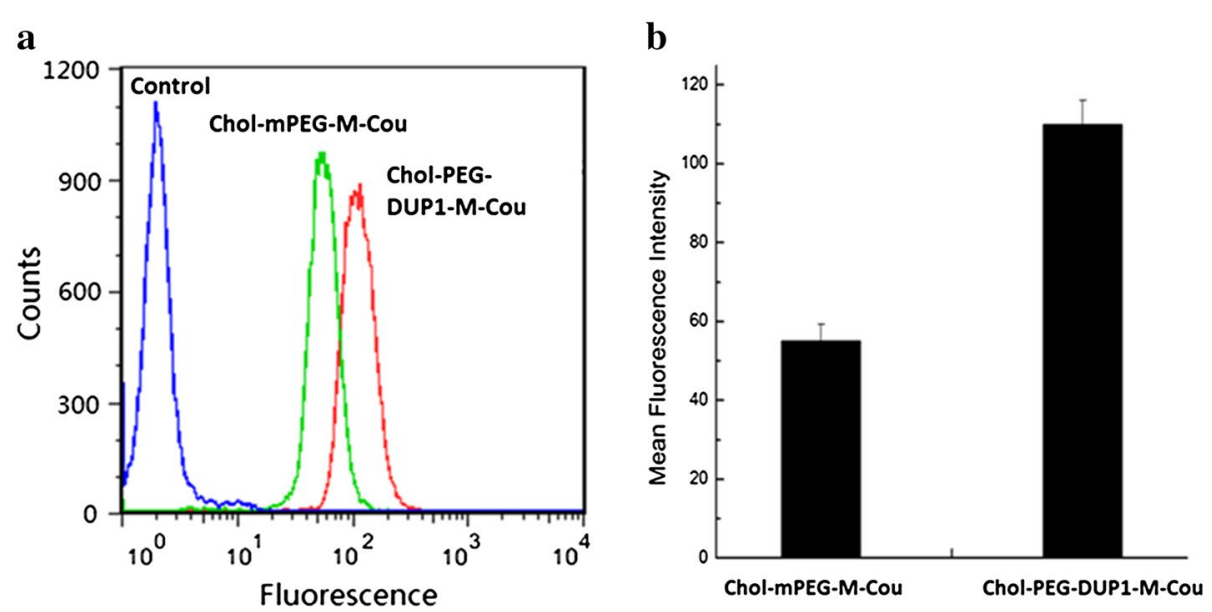

Fig. 5 Different cellular uptake of coumarine-6 loading micelles with or without DUP1 by PC-3 tumor cells. a Intracellular coumarine-6 fluorescence intensities in PC-3 cells after incubation with Chol-PEG-DUP1-MCou (coumarine-6 loaded Chol-PEG-DUP1 micelles), Chol-mPEG-M-Cou (coumarine-6 loaded Chol-mPEG micelles), or empty Chol-PEG-DUP1 micelles (Control); b quantification of the mean fluorescence intensities of intracellular coumarine-6 from Chol-PEG-DUP1-M-Cou or Chol-mPEG-M-Cou, respectively

by cells treated with Chol-PEG-DUP1-M-Cou was increased by 2.08 -fold (mean fluorescence intensity $=54.7$ vs. $113.8, p<0.05)$ compared with that treated with Chol-mPEGM-Cou (Fig. 5). These results indicate that the DUP1 peptide fragments on the surface of micelles indeed enhanced the uptake of the drug (coumarine-6) in tumor cells. Which were further confirmed by fluorescence microscopy images (Fig. 6). Figure 6 is supported Chol-PEG-DUP1-M-Cou could effectively entry PC-3 prostate tumor cells, while less coumarine- 6 was detected in cells that incubated with Chol-mPEG-M-Cou. When the PC-3 tumor cells were pre-incubated by free DUP1 peptides, the cellular uptake of CholPEG-DUP1-M-Cou was obviously decreased, this further confirms the selectivity of Chol-PEG-DUP1 micelles to tumor cells were came from the DUP1 peptide fragments.

\section{In vitro cytotoxicity evaluation}

In vitro cytotoxicity of Chol-PEG-DUP1-M-PTX and free PTX was determined by cell viability assay on PC-3 cells, and the results were shown in Fig. 7. With increase of PTX concentration, cell viabilities were decreased accordingly in all groups, but there was no significant difference between Chol-mPEG-M-PTX and free PTX groups. After $48 \mathrm{~h}$ incubation with the free PTX, Chol-mPEG-M-PTX or Chol-PEG-DUP1-M-PTX, cytotoxicity was measured following the absorbance of the degraded MTT at $570 \mathrm{~nm}$. As shown in Fig. 7, Chol-PEG-DUP1-M-PTX showed significantly higher cytotoxicity than free paclitaxel or Chol-mPEG-M-PTX. The mean concentrations of paclitaxel that caused $50 \%$ cell inhibition $\left(\mathrm{IC}_{50}\right)$ of Chol-PEG-DUP1-M-PTX was decreased to $15.83 \mu \mathrm{g} / \mathrm{mL}$ compared with $68.67 \mu \mathrm{g} / \mathrm{mL}$ of free paclitaxel and $65.76 \mu \mathrm{g} / \mathrm{mL}$ of Chol-mPEG-M-PTX, respectively.

\section{In vitro apoptosis induction effect}

In vitro apoptosis induction effect of Chol-PEG-DUP1-M-PTX was investigated using FCM assay of Annexin V/PI staining was employed to investigate the apoptosis induction effect of Chol-PEG-DUP1-M-PTX, and both early apoptosis (Annexin $\mathrm{V}^{+}$/ 


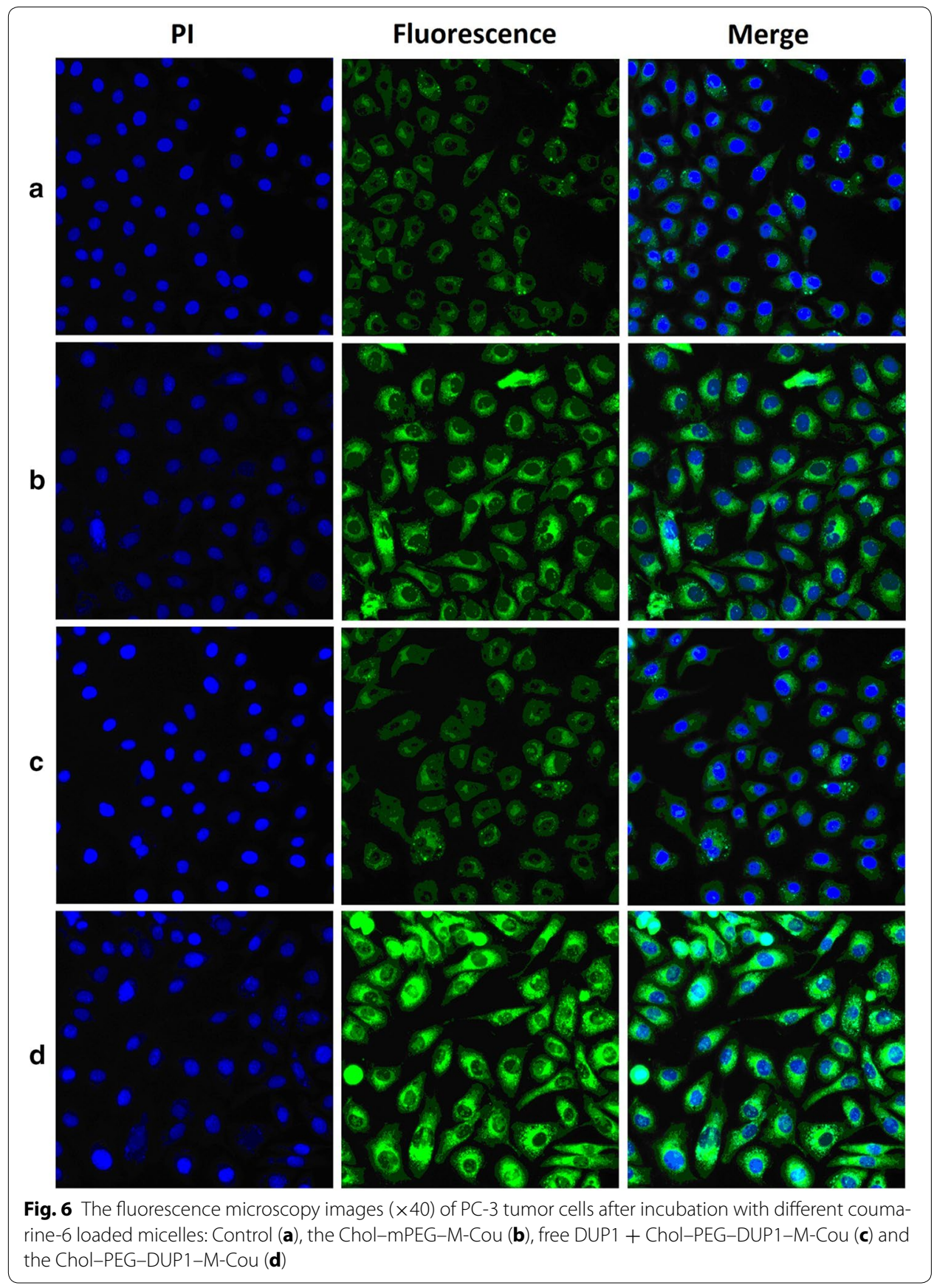

$\mathrm{PI}^{-}$) and late apoptosis (Annexin $\mathrm{V}^{+} / \mathrm{PI}^{+}$) cells were included. According to Fig. 8, the percentage of apoptotic cells in Chol-PEG-DUP1-M-PTX group was $52.62 \pm 7.12 \%$, which was significantly higher than that in free PTX (36.97 $\pm 5.75 \%, p<0.05)$, and NS $(4.01 \pm 0.74 \%, p<0.05)$ groups. There was no significant difference in late apoptosis between the Chol-PEG-DUP1-M-PTX $(9.72 \pm 2.15 \%)$ and free PTX $(9.87 \pm 2.59 \%$, $p<0.05)$ groups, but early apoptotic cells in the Chol-PEG-DUP1-M-PTX group $(43.9 \pm 5.09 \%)$ were more than that in free PTX group $(27.1 \pm 3.64 \%, p<0.05)$. The 


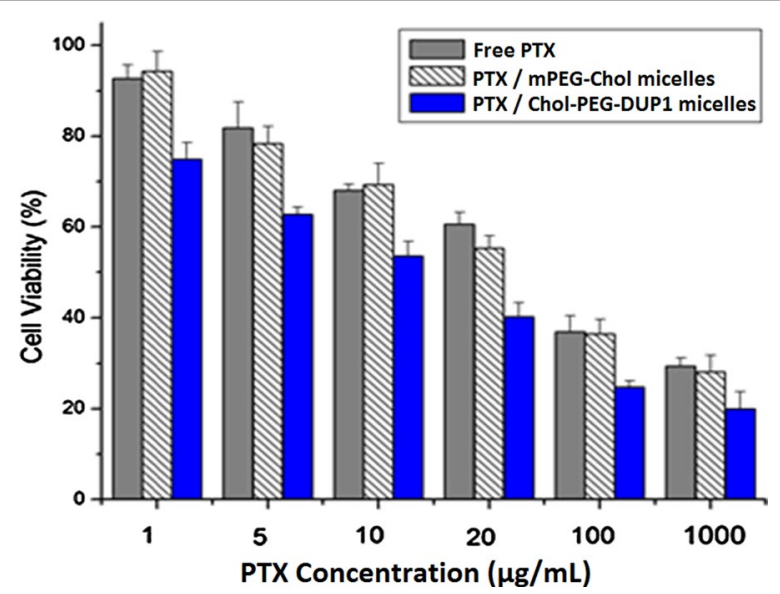

Fig. 7 The in vitro cytotoxicity of the free PTX, Chol-MPEG-M-PTX, and Chol-PEG-DUP1-M-PTX on PC-3 cell lines (48 h). The percentage of viable cells was quantified using the methylthiazoletetrazolium method. Mean values and $95 \%$ confidence intervals derived from three independent experiments are shown, ${ }^{*} p<0.05$
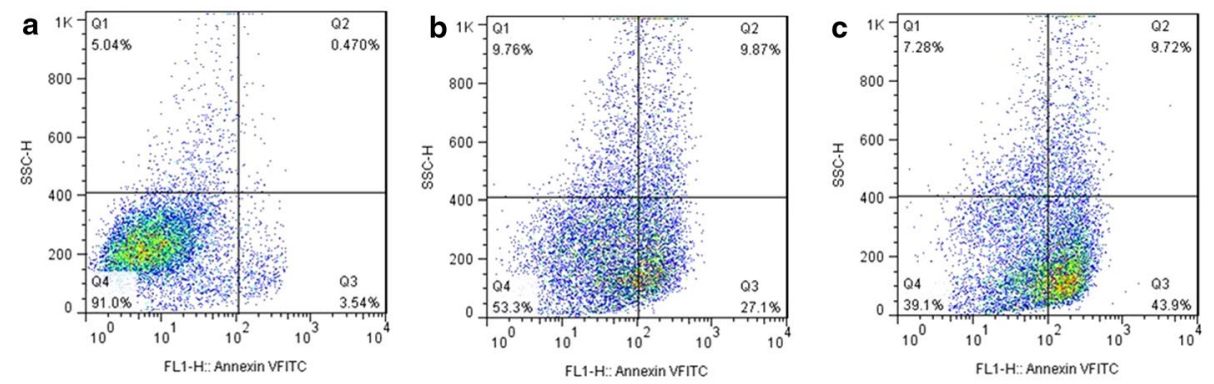

Fig. 8 Flow cytometric analysis of PC-3 cells stained with Annexin V-FITC/PI after treatment with control group (a), $10 \mu \mathrm{M}$ of free PTX (b) or Chol-PEG-DUP1-M-PTX (c)

results of morphological observation and FCM assay suggested that, compared with free PTX, Chol-PEG-DUP1-M-PTX induced more apoptotic cells.

Immunoblotting analysis

To validate the expression of apoptosis related proteins in Chol-PEG-DUP1-M-PTX and free PTX treated PC-3 cells, immunoblotting assays were performed using examples of the death receptor pathway and mitochondrial pathway related to apoptotic proteins. Generally, apoptotic cell death is triggered by either the intrinsic pathway involving mitochondria or by the extrinsic pathway involving death receptors. The death receptor pathway can be initiated by stimulation of members of the death receptor family such as Fas, tumor necrosis factor related apoptosis-inducing ligand (TRAIL), and TNF- $\alpha$. Initial mechanistic studies with Chol-PEG-DUP1-M-PTX and free PTX showed that the drug and drug loaded micelle only slightly increased levels of FasL, Fas-Associated protein with Death Domain (FADD), and cleaved caspase-8 in PC-3 cells (Fig. 9). This suggests that the apoptotic procedure barely involves the death receptor pathway. At the same time, Chol-PEG-DUP1-M-PTX and free PTX increased the amounts of Bax and cytosolic cytochrome c (Fig. 9), indicating that at least part of PTX and DUP1-M-PTX 


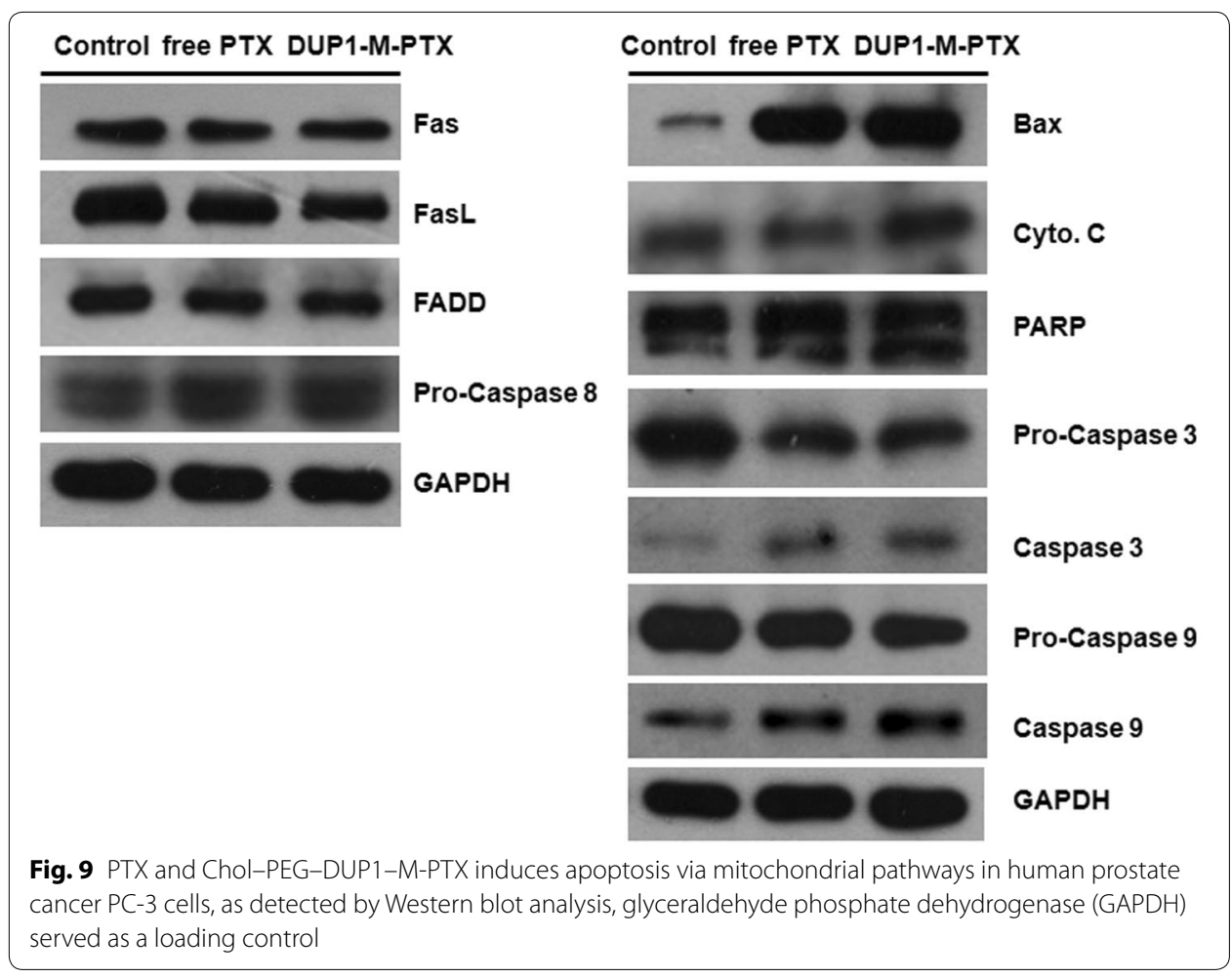

induced apoptosis occurs via mitochondrial pathway. Since the release of cytochrome c from mitochondria can activate the proapoptotic caspase cascade, we investigated whether caspases 3 and 9 are involved. Treating PC-3 cells with PTX and drug loaded micelle increased levels of the cleaved forms of caspases 3 and 9 (Fig. 9). These results provided additional evidence that PTX induced apoptosis mainly occurred in the mitochondrial pathway, and the DUP1 modified micelle could enhance the apoptosis-inducing capacity of PTX to PC-3 prostate cancer cells.

\section{Conclusions}

In conclusion, targeting peptide modified PEG-Chol polymeric micelles, the surfaces of which are conjugated with DUP1 peptide, have been prepared for PSMA negative PCa targeted drug delivery. The reported Chol-PEG-DUP1-M-PTX bearing both small particle size and high encapsulating efficiency. In vitro experiments suggested that Chol-PEG-DUP1-M-PTX had prior cytotoxicity than free drug in the cell proliferation MTT assays, and could inducing more apoptosis. Cellular flow cytometry results and fluorescence spectroscopy images suggest the surface DUP1 modification of the micelles promote the selective uptake by PSMA negative PC-3 cells. Although further in vivo antitumor investigation of Chol-PEG-DUP1-M-PTX is required, the results of our current study represent a meaningful explore in advancing the use of DUP1 peptide modified micelles as a potent strategy to treat PSMA negative prostate cancer. Thus, Chol-PEG-DUP1-M-PTX may serve as a promising candidate for prostate cancer therapy. 


\section{Authors' contributions}

$\mathrm{HC}$ contributed to the whole process of the synthesis, characterization, and in vitro evaluation of the drug loaded micelle, and the preparation of the first edition of the manuscript. LC contributed to in vitro evaluation of the drug loaded micelle, related cell culture work, interpretation of the results, and manuscript editing. FW and XL supervised the whole procedure and also contributed to the data interpretation and revision of the manuscript. XJ contributed to data collection and discussion. All authors read and approved the final manuscript.

\section{Author details}

${ }^{1}$ Department of Gastrointestinal Surgery, Department of Urology, Department of Pharmacy and State Key Laboratory of Biotherapy, West China Hospital, Sichuan University, Chengdu 610041, China. ${ }^{2}$ Department of Pharmacy, Hospital of the University of Electronic Science and Technology of China and Sichuan Provincial People's Hospital, Chengdu 610072, China. ${ }^{3}$ Department of Clinical Pharmacy and Pharmacy Administration, West China School of Pharmacy, Sichuan University, Chengdu 610041, China.

\section{Acknowledgements}

This work was financially supported by the National Natural Science Foundation of China (81402500), China Postdoctoral Science Foundation Funded Project (2014M560720), and Support Foundation of Science and Technology Department of Sichuan Province (2014FZ0039).

\section{Competing interests}

The authors declare that they have no competing interests.

Received: 7 December 2015 Accepted: 10 March 2016

Published online: 22 March 2016

\section{References}

Bostwick D-G, Pacelli A, Blute M, Roche P, Murphy G-P (1998) Prostate specific membrane antigen expression in prostatic intraepithelial neoplasia and adenocarcinoma: a study of 184 cases. Cancer 82:2256-2261

Cai L-L, Qiu N, Li X, Luo K-L, Chen X, Yang L, He G, Wei Y-Q, Chen L-J (2011) A novel truncated basic fibroblast growth factor fragment-conjugated poly(ethylene glycol)-cholesterol amphiphilic polymeric drug delivery system for targeting to the FGFR-overexpressing tumor cells. Int J Pharm 408:173-182

Crawford E-D (2003) Epidemiology of prostate cancer. Urology 62:3-12

Dharap S-S, Wang Y, Chandna P, Khandare J-J, Qiu B, Gunaseelan S, Sinko P-J, Stein S, Farmanfarmaian A, Minko T (2005) Tumor-specific targeting of an anticancer drug delivery system by LHRH peptide. Proc Natl Acad Sci USA 102:12962-12967

Gong CY, Wei XW, Wang XH, Wang YJ, Guo G, Mao YQ, Luo F, Qian ZY (2010) Biodegradable self-assembled PEGPCL-PEG micelles for hydrophobic honokiol delivery: I. Preparation and characterization. Nanotechnology. doi:10.1088/0957-4484/21/21/215103

Gong C-Y, Wang Y-J, Wang X-H, Wei X-W, Wu Q-J, Wang B-L, Dong P-W, Chen L-J, Luo F, Qian Z-Y (2011) Biodegradable self-assembled PEG-PCL-PEG micelles for hydrophobic drug delivery, part 2: in vitro and in vivo toxicity evaluation. J Nanopart Res 13:721-731

Gong C-Y, Deng S-Y, Wu Q-J, Xiang M-L, Wei X-W, Li L, Gao X, Wang B-L, Sun L, Chen Y-S (2013) Improving antiangiogenesis and anti-tumor activity of curcumin by biodegradable polymeric micelles. Biomaterials 34:1413-1432

He G, He Z-Y, Zheng X, Li J-M, Liu C, Song X-R, Ouyang L, Wu F-B (2012) Synthesis, characterization and in vitro evaluation of self-assembled poly(ethylene glycol)-glycyrrhetinic acid conjugates. Lett Org Chem 9:202-210

He ZY, Wei XW, Luo M, Luo ST, Yang Y, Yu YY, Chen Y, Ma C-, Liang X, Guo FC et al (2013) Folate-linked lipoplexes for short hairpin RNA targeting claudin-3 delivery in ovarian cancer xenografts. J Control Release 172:679-689

Iyer A-K, Khaled G, Fang J, Maeda H (2006) Exploiting the enhanced permeability and retention effect for tumor targeting. Drug Discov Today 11:812-818

Jain R-K, Stylianopoulos T (2010) Delivering nanomedicine to solid tumors. Nat Rev Clin Oncol 7:653-664

Li J-M, He Z-Y, Yu S, Li S-Z, Ma Q, Yu Y-Y, Zhang J-L, Li R, Zheng Y, He G, Song X-R (2012) Micelles based on methoxy poly(ethylene glycol)-cholesterol conjugate for controlled and targeted drug delivery of a poorly water soluble drug. J Biomed Nanotechnol 8:809-817

Li B, Ma Q, He G, Song X-R, Wu F-B, Zheng Y, Zeng S, Liu C, Ren W (2013) Synthesis and characterization of a novel methoxy poly(ethylene glycol)-Tat peptide-chitosan copolymers. Colloid Polym Sci 291:1319-1327

Liu H, Moy P, Kim S, Xia Y, Rajasekaran A, Navarro V, Knudsen B, Bander N-H (1997) Monoclonal antibodies to the extracellular domain of prostate-specific membrane antigen also react with tumor vascular endothelium. Cancer Res 57:3629-3634

Liu L-H, Guo K, Lu J, Venkatraman S-S, Luo D, Ng K-C, Ling E-A, Moochhala S, Yang Y-Y (2008) Biologically active core/shell nanoparticles self-assembled from cholesterol-terminated PEG-TAT for drug delivery across the blood brain barrier. Biomaterials 29:1509-1517

Ma Q, Li B, Yu Y-Y, Zhang Y, Wu Y, Ren W, Zheng Y, He J, Xie Y-M, Song X-R (2013) Development of a novel biocompatible poly(ethylene glycol)-block-poly(gamma-cholesterol- $\gamma$-glutamate) as hydrophobic drug carrier. Int J Pharm 445:88-92

Muggia F-M (1999) Doxorubicin-polymer conjugates: further demonstration of the concept of enhanced permeability and retention. Clin Cancer Res 5:7-8

Nanus D-M, Milowsky M-I, Kostakoglu L, Smithjones P-M, Vallabahajosul S (2003) Clinical use of monoclonal antibody HuJ591 therapy: targeting prostate specific membrane antigen. J Urol 170:S84-\$88

Parkin D-M, Bray F-I, Devesa S-S (2001) Cancer burden in the year 2000. The global picture. Eur J Cancer 37:S4-S848 
Renneberg H, Friedetzky A, Konrad L, Kurek R, Weingartner K, Wennemuth G, Tunn UW, Aumuller G (1999) Prostate specific membrane antigen (PSM) is expressed in various human tissues: implication for the use of PSM reverse transcription polymerase chain reaction to detect hematogenous prostate cancer spread. Urol Res 27:23-27 Sandblom G, Varenhorst E (2001) Incidence rate and management of prostate carcinoma. Biomed Pharmacother 55:135-143

Silver D-A, Pellicer I, Fair W-R, Heston W-D, Cordon-Cardo C (1997) Prostate-specific membrane antigen expression in normal and malignant human tissues. Clin Cancer Res 3:81-85

Sternberg C-N (2003) What's new in the treatment of advanced prostate cancer? Eur J Cancer 39:136-146

Torchilin V-P, Lukyanov A-N, Gao Z-G, Sternberg B-P (2003) Immunomicelles: targeted pharmaceutical carriers for poorly soluble drugs. Proc Natl Acad Sci USA 100:6039-6044

Wagner V, Dullaart A, Bock A-K, Zweck A (2006) The emerging nanomedicine landscape. Nat Biotechnol 24:1211-1218

Wu Y, Ma Q, Song X-R, Zheng Y, Ren W, Zhang J-K, Ouyang L, Wu F-B, He G (2012) Biocompatible poly(ethylene glycol)poly(Y-cholesterol-L-glutamate) copolymers: synthesis, characterization, and in vitro studies. J Polym Sci A Polym Chem 50:4532-4537

Ross J-S, Sheehan C-E, Fisher H-A-G, Kaufman R-P, Kaur P, Gray K, Webb I, Gary S-G, Mosher R, Kallakury B-V-S (2003) Correlation of primary tumor prostate-specific membrane antigen expression with disease recurrence in prostate cancer. Clin Cancer Res 9:6357-6362

Zeng S, Wu F-B, Li B, Song X-R, Zheng Y, He G, Peng C, Huang W (2014) Synthesis, characterization, and evaluation of a novel amphiphilic polymer RGD-PEG-Chol for target drug delivery system. Sci World J. doi:10.1155/2014/546176

Zhang J-K, Fang D-L, Ma Q, He Z-Y, Ren K, Zhou R, Zeng S, Li B, He L-L, He G (2014) Dual-functional PEl-poly(Y-cholesterolL-glutamate) copolymer for drug/gene co-delivery. Macromol Chem Phys 215:163-170

Zitzmann S, Mier W, Schad A, Kinscherf R, Askoxylakis V, Kramer S, Altmann A, Eisenhut M, Haberkorn U (2005) A new prostate carcinoma binding peptide (DUP-1) for tumor imaging and therapy. Clin Cancer Res 11:139-146

\section{Submit your manuscript to a SpringerOpen ${ }^{\circ}$ journal and benefit from:}

- Convenient online submission

- Rigorous peer review

- Immediate publication on acceptance

- Open access: articles freely available online

- High visibility within the field

- Retaining the copyright to your article

Submit your next manuscript at $\mathbf{s p r i n g e r o p e n . c o m ~}$ 